\title{
Nutrition Policy in the Post-devolution Context in Pakistan: An Analysis of Provincial Opportunities and Barriers*
}

\author{
Shehla Zaidi, Shandana Khan Mohmand, Noorya Hayat, \\ Andres Mejia Acosta and Zulfiqar A. Bhutta
}

\begin{abstract}
In this article we take a comparative look at strategic opportunities and barriers for action on nutrition in Pakistan's four provinces in the post-devolution context. Provinces have faced historically common constraints of lack of a comprehensive policy and minimal allocations by the state, driven by low visibility of nutrition, siloed working of sectors and weak coalitions. Provinces also face common contextual impediments of poverty, patriarchy, and inadequate health and WASH coverage, with two provinces also constrained by inequitable power structures. Recent focusing events have provided a window of opportunity to the provinces for action on nutrition leading to definite movement towards horizontal coordination for nutrition, upscaled funding and stronger vertical integration. However, there are variations in the extent of coalition building on nutrition, supportive leadership, governance and community outreach. The Pakistan experience shows that strategising for nutrition needs to move beyond a closely tailored national policy to accounting for sub-national potential and constraints.
\end{abstract}

\section{Background, intent and methods}

Malnutrition in Pakistan is high, with 31.5 per cent of children under five years of age being underweight, 43.7 per cent stunted, and 15.1 per cent wasted. Sub-clinical deficiencies of iron, vitamin A, zinc and iodine are rampant (NNS 2011). Undernutrition is a chronic issue with little evidence of change over the past decade (NNS 2011 and 2001), but there is provincial variation in its prevalence. Rates of undernutrition are highest in Sindh province, followed by Balochistan and Khyber Pukhtunkhwa (KPk), and are the lowest in Punjab.

A year before the National Nutrition Survey (NNS) 2011 reported these provincial differentials, the formulation of appropriate responses to undernutrition had already become a provincial responsibility. The post-2010 devolution context raises an important opportunity for revitalising the nutrition agenda in Pakistan. In April 2010 the parliament of Pakistan passed the 18th Amendment, which sought to return the Constitution to its 1973 formulation by purging it of later amendments introduced by Zia-ul-Haq's military regime, and, in the process, also empowered provinces as never before by devolving 17 ministries from the centre to the provinces. Key ministries related to nutrition such as Health, Education, Food, Agriculture, Women's Development and Social Welfare were put under provincial control. This was the first time that such power had been given to the provinces, since past decentralisation reforms had generally bypassed the provincial tier by decentralising administrative responsibility for most social services directly to the sub-provincial district level. At the same time, there were significant changes in funding modalities. The financial status of provincial governments in Pakistan is dependent on federal transfers of tax revenues to the provinces through National Finance Commission (NFG) Awards. While the 2010 devolution shifted the financing responsibility for devolved ministries to provincial governments, provincial funding allocations increased substantially as a result of the 7th NFG Award of 
Table 1 Contextual resources and constraint for nutrition (\%)

\begin{tabular}{llllll}
\hline Resources & Punjab & Sindh & KPk & Balochistan & Pakistan \\
\hline Food security resources & & & & & \\
Agriculturally productive land & & & & & \\
Land ownership & $83^{1}$ & $27.3^{1}$ & $16.5^{1}$ & $3.2^{1}$ & $30^{1}$ \\
Poverty level & 73.9 & 41.4 & 67.65 & 47.5 & 44.45 \\
Food secure households & $26^{2}$ & $31^{2}$ & $29^{2}$ & $48^{2}$ & $33^{2}$ \\
\hline Caregiver resources & $40.5^{3}$ & $28.2^{3}$ & $68.5^{3}$ & $36.5^{3}$ & $41.9^{3}$ \\
Female literacy rate & & & & & \\
Female allowed to work for livelihood & $51^{4}$ & $46^{4}$ & $33^{4}$ & $19^{4}$ & $46^{4}$ \\
Females with bank accounts & $51^{5}$ & $40-46^{5}$ & $40-45^{5}$ & $35-46^{5}$ & $47-49^{5}$ \\
Female unemployment rate & $5.35^{6}$ & $6.6^{5}$ & $7-13^{5}$ & $8-10^{5}$ & $6-7^{5}$ \\
\hline Social environment & & $16.60^{6}$ & $8.08^{6}$ & $8.88^{6}$ \\
Access to improved drinking water & $93^{4}$ & $89^{4}$ & $69^{4}$ & $47^{4}$ & $87^{4}$ \\
Use of hygienic sanitation facility & $82^{3}$ & $72^{3}$ & $84^{3}$ & $46^{3}$ & $78^{3}$ \\
Measles vaccination of children 12-23 months & $65.1^{7}$ & $50.7^{7}$ & $56.6^{7}$ & $54^{7}$ & $59.9^{7}$ \\
Pregnant women received pre-natal care & $60.9^{7}$ & $70.4^{7}$ & $51.3^{7}$ & $40.7^{7}$ & $60.9^{7}$ \\
Pregnant women received post-natal care & $40^{7}$ & $60^{7}$ & $27.3^{7}$ & $40.5^{7}$ & $43.1^{7}$ \\
\hline
\end{tabular}

Source (1) Federal Bureau of Statistics 2009-10; (2) Social Policy and Development Centre 2004; (3) National Nutrition Survey 2011; (4) Pakistan Social and Living Measurement 2010-2011; (5) USAID 2012; (6) Labor Force Survey 2010-11; (7) Pakistan Demographic and Health Survey 2006-07.

2009, which historically increased provincial share of resources to 56 per cent and also introduced a more equitable distribution formula, benefiting the smaller provinces with a shift from awarding on the basis of population to also factor in backwardness, inverse population density and revenue collection/generation (Sabir 2011). Overall it represents an additional budget of 20.4 per cent for Punjab, 24.5 per cent for Sindh, 58 per cent for KPk and 132 per cent for Balochistan (ibid.).

What has this meant for nutrition in the postdevolution scenario? In this article we answer this question by taking a comparative look at strategic opportunities for and barriers to action on nutrition in Pakistan's four provinces Khyber Pukhtunkhwa (KPk), Punjab, Balochistan and Sindh - in the post-devolution context. In particular we focus on chronic and acute malnutrition in pregnant and lactating women and in children under the age of five, the groups most at risk for undernutrition.
We applied a nutrition governance framework (Mejia Acosta and Fanzo 2012) focused on the capabilities of relevant stakeholders and the broad parameters of the existing institutions and policy frameworks in which they operate. It focuses in particular on: (a) cooperation between different stakeholders in the design, formulation and implementation of nutrition policy; (b) extent of integration between policy formulation and implementation at different levels of government; and (c) the extent to which this cooperation and integration is held together by adequate funding mechanisms. It is supplemented by a policy analysis model that cyclically links process, actors, context and content of nutrition initiatives at design and implementation levels (Walt and Gilson 1994). Qualitative research methods were applied combining 84 in-depth interviews and seven focal group discussions with stakeholders from the state, donor agencies, civil society organisations (CSOs) and nutrition experts, supplemented with document review of published and grey literature. Consultative provincial and 
national roundtables were held to validate and supplement findings of desk review and interviews.

\section{Provincial contexts contributing to undernutrition}

It is important to understand the contextual commonalities and dissimilarities in the provinces that contribute to undernutrition (see Table 1). Undernutrition is compounded in almost all provinces by poverty, patriarchy, steep inflation in food prices, and insufficient availability of safe water, proper sanitation, and promotive health services for mother and child. Of the four provinces, Punjab has the best food security resources with surplus food production, but undernutrition levels and household food insecurity are higher than expected. Southern Punjab accounts for much of the undernutrition burden and this is due to greater poverty, land inequality and less access to social services, with child undernutrition up to 52.9 per cent in southern districts as compared to a provincial total of 29.8 per cent (MICS 2011). Paradoxically, while Sindh is the second most secure in terms of food resources, it suffers from the highest rates of food insecurity and undernutrition.

Explanations for this lie in more entrenched power structures as manifested by a comparatively higher level of landlessness and poverty, and compounded by insufficient access to social sector services in disadvantaged districts. In KPk the social exclusion of women and high levels of insecurity, violence and conflict are the largest issues, but it is not food insecure based on a more equitable distribution of land and greater crop diversification - and has lower levels of undernutrition than Sindh. Balochistan faces the toughest contextual challenges with high food insecurity, lack of water access, inadequate outreach of social sector services and a patriarchal tribal power structure. This is reflected in its very high level of undernutrition. All three smaller provinces are currently suffering from very high levels of conflict and insecurity. Environmental threats have recently emerged, as seen by recent flash floods, and threaten all four provinces.

\section{The policy stream for nutrition: understanding, ownership and funding}

It is important to understand the depth and nature of action on nutrition in the predevolution context as this has important implications for the opportunities and challenges that the provinces now face. In countries that have been successful in reducing nutrition, such as Brazil and Peru, important factors have been the political championing of nutrition at the highest level, which has been successful in leveraging nutrition as a cross-sectoral agenda, supported by strong coordination, central convening structure, and mainstreaming on nutrition indicators in sectoral planning (Mejia Acosta and Fanzo 2012).

Low policy profile: Nutrition traditionally has been a low priority area in Pakistan. Although nutrition was institutionalised in the Planning Commission in 1973 there has been little movement and it continues to lack a national policy and strategy plan. Nutrition as a silent hidden issue had low visibility for the political and bureaucratic leadership. The very nature of nutrition does not offer quick, short-term wins but instead relies on a cohesive development vision which has not been forthcoming, with development priorities in Pakistan dominated by economic growth, food security and infrastructure-dominated projects. Moreover, nutrition is a multifaceted subject relying on cross-sectoral implementation across a number of sectors. However, understanding of nutrition remains weak across sectors with narrow linkage to health, food or poverty in all provinces although with relatively better recognition of cross-sectoral action in Balochistan. In addition, the need for connectivity across sectors also makes it a complex subject as the relevant sectors can neither deliver alone nor have the mandate to instigate and coordinate action on nutrition, as discussed in further detail below. After four decades of nutrition institutionalisation, there is still a conspicuous absence of a nutrition policy and strategy. A Micro-Nutrient Strategic Plan and a draft Pakistan Integrated National Strategy have been developed supported mainly by development partners but they lack state funding and operational plans.

\section{Narrow operationalisation and inadequate funding:} Although nutrition was institutionalised as a subject with reliance on different sectors, as happened in other countries, subsequent operationalisation was both slow and narrow. Operationalisation of nutrition came three decades later in 2005 and was narrowly delegated as a sub-set of health activities with a Nutrition Wing set up in the Ministry of Health. Even after 
operationalisation nutrition remained confined to small-scale PC-1 supported initiatives (Planning Commission projects) led by donor funds and it was not integrated into operational sectoral budgets nor had funding led from the state. Interventions revolved around the establishment of Baby-Friendly Hospitals for promoting newborn breastfeeding, nutrition corners at health facilities for nutrition-related advice, distribution of vitamin A supplements to children and iron and folic acid supplements to pregnant women, and the management of acute malnutrition. Food fortification was implemented with training, equipment and commodities support directed towards food processors in the private sector. School Feeding pilots targeted at girls 6-11 years of age in disadvantaged rural districts were implemented in all provinces. Projects were funded by UN agencies, the World Food Programme and international nongovernmental organisations (NGOs), and have halted when donor funds have dried up.

Food, not nutrition: Within the federal government the emphasis of economists and senior bureaucrats has historically tilted towards the more visible issue of food security. Federally driven food distribution schemes have included a card-based rationing system for the urban poor replaced subsequently by wheat subsidy and distribution to ensure the availability of flour on the market at controlled prices for both the urban and the rural poor. Recently there has been distribution of food rations to flood victims through the Provincial Disaster Management Agencies (PDMAs) in all provinces. Food distribution schemes remain popular as a politically visible agenda item among politicians from different political parties due to observable, tangible and immediate benefits to the electorate constituencies. Hunger in the slogan and manifesto of the ruling Pakistan's Peoples Party (PPP) provides a basis for strong championing by the government and has resulted in the institution of the Food Security Task Force in 2008 followed by the Ministry of Food Security. The political importance of food is seen at least in two provinces. In Punjab, the provincial Pakistan Muslim League-Nawaz (PML-N) government has initiated schemes for hunger independently from the federal food initiatives of the PPP government, the sasti roti, or cheap bread and sarkari kitchen, or state kitchen programmes. In Sindh, private philanthropies have emerged in major urban areas for the daily provision of cooked food to the poor, as a response to growing inflation of the costs of essential food items. Attention to food security provides potential for coalition around nutrition; however, there have been as yet little connects of food security with the larger issue of undernutrition.

Focusing events towards nutrition: The flash floods of 2010 and 2011 visibly highlighted mother and child undernutrition in affected areas of all four provinces and instigated a coordinated cluster response. Around the same time a Pakistan Integrated Nutrition Strategy draft was formed at the federal level spearheaded by UNICEF in the wake of the global Scaling Up Nutrition (SUN) movement. The release of the NNS in early 2012 backed with unusual media publicity further shot the undernutrition issue into policy prominence with a call for action backed by researchers, media and development partners. Lastly, the provincial devolution of 2011 provided development partners with an easier direct engagement process with implementers, sidestepping the slower centralised planning processes. Nutrition hence became a new public policy agenda spearheaded by development partners. However, enhanced recognition and wider interpretation of nutrition by government is questionable as discussed below.

\section{Horizontal coordination and inter-sectoral mandate}

Housing and leadership for coordination: Horizontal coordination is constrained by interdepartmental gulfs created by siloed working, lack of both time and mandate for coordination, and poor circulation of documents. Health continues to be the principal active sector and the database and monitoring for nutrition are also within Health rather than in a central coordinating structure; however, provincial government departments apprehend that concentrating intersectoral authority in one specific department would make other departments less keen to buy in. There is also low buy-in across the provinces for jointly funded initiatives, with a preference for sector-specific budgets and plans, with a general preference for loose coalition rather than substantial horizontal coordination. Desire for continued power and funds, and compounded by past experience of collective failure in Pakistan's Social Action Programme due to centralised slow bureaucratic and funding releases. Although devolution of 
health, education, food and agriculture took place in 2011, to date no formal structure to house nutrition has been nominated at the provincial level. Provincial Planning and Development Departments (P\&DDs) are responsible for coordinating subjects across departments to develop a common provincial development framework, acting as counterparts to the federal level's National Planning Commission (NPG). However, despite the existence of a nutrition wing in the NPC, counterpart nutrition wings have not yet been created in any of the provincial P\&DDs nor has responsibility for nutrition been attributed to the different units within P\&DDs that are responsible for coordination with different sectors.

Further complicating the issue of horizontal coordination at the provincial level is the fact that while several ministries relevant to nutrition were devolved to the provinces in 2011, certain nutrition-relevant programmes have been retained at the federal level, such as the Benazir Income Support Programme (BISP), the National Disaster Management Agency (NDMA) and the Ministry of Food Security. This means that the provinces also have to coordinate with federal counterparts, requiring leadership capacities for wider coordination and effective coordination platforms at the national level.

Nutrition stakeholders: There has been little horizontal coordination for nutrition in the past and hence there are few actors meaningfully involved. Within the provincial departments Health has traditionally been the most active, employing preventive health strategies targeted at women and children, although activities have been low scale, interrupted and with a changing focus over time. Provincial Food Departments have made a negligible contribution to salt iodisation with schemes operationalised within the Health Department while market quality assurance of fortified foods and pricing has overlapping and unclear roles between Health and Food. Punjab is the only province to have set up a Food Regulation Authority to pull together quality assurance functions under a single entity. Similarly, school-feeding pilots have been managed by the Education Department supported by the World Food Programme, and there is lack of connects with Health for nutrition awareness and child preventive-health interventions and with poverty alleviation schemes such as BISP for targeting poor households. The Tawana Project providing freshly prepared food and dietary education at girls schools and working though joint funding lines was the only multisectoral initiative involving multiple partners such as Women's Development, Bait-ul-Mal and NGOs. However it was affected by turf-setting issues and low district ownership, which led to discontinuation two years into the programme despite reduction in undernutrition in schoolgirls from 24 to 18 per cent and increase in mother knowledge from 4 to 35 per cent (Badruddin et al.2008; and see Kahn et al., this IDS Bulletin). Other sectors have only recently been drawn into nutrition coalition and the definition of their role is still emerging.

Even outside the state, coalitions around nutrition are narrow in all provinces, consisting mainly of $\mathrm{UN}$ agencies, with varying participation by multilaterals and international NGOs. CSOs have had limited involvement as passive contractees of donor agencies, but nutrition as an agenda is yet to be internalised within the CSOs. Only in Sindh have coalitions also visibly included nutrition experts and the paediatric community across both the public and private sectors. The efforts of individual paediatricians have resulted in sustaining nutrition-related health initiatives in public sector hospitals after the end of UN funding, despite the lack of ownership of these initiatives by district governments and provincial health departments. A clear disconnect is the lack of strategic coordination of the non-state sectors by the state with dialogue that is infrequent and usually mediated by development partners.

Emerging opportunities: Experience of dealing with the floods over the last three years has provided experience, linkages and a mechanism for an integrated cluster approach that allows for operational plans to be aligned while keeping budget lines independent. There is also increased fiscal space in the provinces as a result of the 7th National Finance Commission award, although this is yet to be captured for nutrition. Recently, pressure by development partners has resulted in some preliminary moves towards provincial integrated nutrition strategies and the establishment of provincial intersectoral nutrition committees headed by the P\&DDs. Levels of interest vary across the respective P\&DDs, with Punjab having made the fastest progress in constituting an intersectoral nutrition committee. However, there is still 
Table 2 Mother and child care: micro-nutrient supplementation, feeding practices, malnutrition management (\%)

\begin{tabular}{|c|c|c|c|c|c|}
\hline Interventions & Punjab & Sindh & KPk & Balochistan & Pakistan \\
\hline Exclusive breastfeeding up to 6 months & $18^{1}$ & $10^{1}$ & $47^{1}$ & $27^{1}$ & $13^{1}$ \\
\hline Complementary feeding 6-8 months & $49.6^{1}$ & $63.2^{1}$ & $36.1^{1}$ & $48.6^{1}$ & $51.8^{1}$ \\
\hline Handwashing with soap & $57.8^{1}$ & $56.2^{1}$ & $62.3^{1}$ & $52.3^{1}$ & $57.6^{1}$ \\
\hline Contraceptive prevalence rate (modern methods) & $23.1^{2}$ & $22^{2}$ & $18.7^{2}$ & $13.4^{2}$ & $21.7^{2}$ \\
\hline Vitamin A supplementation & $81.3-91.6^{3}$ & $83.7^{3}$ & $77.8^{3}$ & $72.6^{3}$ & $78-92^{3}$ \\
\hline De-worming & $78.1^{1}$ & $71.6^{1}$ & $87.9^{1}$ & $56.5^{1}$ & $77.1^{1}$ \\
\hline Percentage of salt iodised & $78.8^{1}$ & $51.8^{1}$ & $63.6^{1}$ & $40.8^{1}$ & $69^{1}$ \\
\hline
\end{tabular}

Source (1) National Nutrition Survey; (2) Pakistan Demographic and Health Survey; (3) Vitamin A Supplementation Survey, Aga Khan University and Micronutrient Initiative.

generally a low level of support within the P\&DDs to take on primary responsibility for nutrition, and a lack of inclusion of the non-state sector. In at least two provinces the new momentum is being interpreted as multisectoral coordination for health activities rather than the larger agenda of cross-sectoral action with visible pro-nutrition planning in each sector.

\section{Vertical integration of existing nutrition initiatives: gaps between design and implementation}

The Department of Health's main interventions include vitamin A supplementation to children, iron and folate provision to mothers, and counselling on infant and young child feeding (Table 2). There have also been additional donorfunded small-scale interventions as mentioned earlier but these have lacked continuity. Vitamin A supplementation has achieved comparatively better results across all provinces, due largely to effective horizontal coordination with the federally run polio immunisation programme. However, gaps between reported and actual immunisation levels are equally likely to affect the coverage of vitamin A supplementation and actual figures may be lower. Other interventions have been less well covered due to lack of cohesive planning for nutrition, weak staff capacity and low community outreach. There are interprovincial variations in the coverage of the Department of Health's initiatives, with Balochistan facing the toughest outreach access issues due to low population density, followed by similar access issues in remote districts of Sindh and KPk. Political appointments and low accountability are particularly evident in Sindh and Balochistan, hampering effective implementation. More recently, the Health Departments in all provinces, with development partner support, have expanded the range of costeffective nutrition interventions; however, ownership is uncertain as major funding will come from a project-focused development budget mainly funded by donors. Post-devolution, some strides have been made in Punjab and KPk where nutrition is integrated within other programmes, increasing chances for sustainability, but it continues to be supported mainly by donor funds. Sindh and Balochistan have instead put up siloed donor-supported nutrition programme within Health, thus increasing chances of discontinuity on the termination of funding.

Food fortification: Salt iodisation in Pakistan has helped reduce iodine deficiency but with varying success rates in the provinces (Table 2). Punjab has the highest rate of 78.8 per cent, which even in the absence of legislation is due to a strong level of cooperation between provincial and district governments. In $\mathrm{KPk}$ the 63.6 per cent iodised salt availability has been due to strong cooperation by several district governments, growing community demand and supportive legislations in place. Conversely, Sindh and Balochistan, despite the presence of supportive district legislations for fortification, have had lower coverage rates due to weak district governance and inadequate private sector presence in the remoter districts. In all provinces, because of low recognition for undernutrition, government support for operational commodity costs has not been forthcoming, leading to supply breaks when 
international agency funding tapers off.

School feeding: School-feeding pilots have differences in scale and ownership across provinces. Provincial Education Departments, as seen also with Health Departments, have a welldeveloped administrative presence at the district level and better continuity is seen in initiatives involving them: poor district ownership was one of the factors behind the discontinuation of the Tawana Project, which was not operationalised through the Education Department. A strong administrative culture is also important, as seen in Punjab where this has been responsible for minimising breaks in food supply, while weak district accountability weakens responses, particularly in Sindh and Balochistan. However, capacity for screening and monitoring child nutrition through school feeding is weak and is undermined by a lesser focus on nutrition as compared to the more obvious benefits of school enrolment.

\section{Discussion and conclusion}

Provinces face certain common challenges for spearheading nutrition work. Nutrition has had low ownership by the state, minimal allocations and lack of a comprehensive policy by the state. This has been due to the lack of a common construct, a narrow operationalisation within one sector, low visibility and weak coalitions around nutrition. Additionally, contextual challenges of poverty, patriarchy, inequitable land holding, suboptimal roll-out of preventive health and water, sanitation and hygiene (WASH) strategies, and environmental disaster are common impediments across the provinces, with heavier contextual challenges in Balochistan, followed by Sindh, KPk and then Punjab. Yet, there is definite, though highly variable, drive within the provinces towards developing nutrition interventions. Recent focusing events have propelled the nutrition agenda into the policy limelight with movement in the provinces towards an integrated state-led strategic framework that can coordinate and support the work of various stakeholders. However, instigation for nutrition being led by donors and the lack of a central housing structure for nutrition raises questions of effective and sustainable coalitions.

The provinces also have varying potential to deal with nutrition. Punjab has integrated nutrition within Health, has a supportive stance from state actors, and strong administrative control over implementation; however, movement on nutrition remains confined to Health, which will undermine nutrition work. KPk has reorganised its Health Department around nutrition-related issues and both sustainability and reforms are high on the provincial development agenda, but nutrition is yet to be a visible cross-sectoral agenda and implementation is handicapped by remote access in certain districts. Sindh and Balochistan are less well positioned. Weak crosssectoral coalition, low district accountability and weak governance in Sindh is likely to undermine nutrition, although it is better positioned than Balochistan due to stronger coalition building among sectors. Balochistan is facing the toughest contextual challenges for nutrition among all provinces and has low district accountability challenges.

Our findings largely conform to global literature on policy-related success and constraints affecting undernutrition. Institutional and political challenges, in particular lack of unity on the construction of nutrition policies, institutional homelessness, a large and fragmented community and narrow operationalisation emerge as the primary constraint to improvement of undernutrition rather than technical capacity (Levinson 2003; Morris et al. 2008; Natalicchio et al. 2009; Rogers 2002). In addition, we find that weak administrative control, as seen in some of the provinces, will blunt results even if effective horizontal coordination is achieved. Furthermore, in contrast to the common perception supported by the SUN movement that sound national policies are enough, we recognise the value of detailed sub-national-level work and argue that sub-national potential and constraints need to be taken into account when strategising for nutrition. 


\section{Notes}

* The material presented in this article was collected for a joint AKU-IDS project on 'Analysis of the Political Economy of Reducing

\section{References}

Badruddin, Salma Halai; Agha, Ajmal; Peermohammad, Habib; Rafique, Ghazala; Khan, Kausar S. and Pappas, Gregory (2008) 'Tawana Project - School Nutrition Program in Pakistan - its Success, Bottlenecks and Lessons Learned, Asia Pac J Clin Nut 17.S1: 357-60

Levinson, James (2003) 'Institutionalization of Nutrition', in Stuart Gillespie, Milla McLachlan, and Roger Shrimpton (eds), Combating Malnutrition: Time to Act. World Bank-UNICEF Nutrition Assessment, Washington DC: World Bank: 101-7

Mejia Acosta, Andres and Fanzo, Jessica (2012)

'Fighting Maternal and Child Malnutrition: Analysing the Political and Institutional Determinants of Delivering a National Multisectoral Response in Six Countries', mimeo, Brighton: IDS

MICS (2011) Multiple Indicator Cluster Survey, Punjab Bureau of Statistics Planning and Development Department Government of Punjab, Khyber Pukhtunkhwa

Morris, S.S.; Cogill, B. and Uauy, R. (2008) 'Effective International Action against
Undernutrition in Pakistan', funded by the Department for International Development (DFID).

Undernutrition: Why has it Proven so Difficult and What can be Done to Accelerate Progress?', The Lancet 371.9612: 608-21 Natalicchio, Marcela; Garrett, James; MennoSibanda, M.; Ndegwa, Steve and Voorbraak, Doris (eds), (2009) Carrots and Sticks: The Political Economy of Nutrition Policy Reforms, HNP Discussion Paper, Washington DC: World Bank NNS (2011) National Nutrition Survey of

Pakistan, Islamabad: Government of Pakistan, Aga Khan University and UNICEF

Rogers, Beatrice L. (2002) 'Health and Economic Consequences of Malnutrition', Background Papers World Bank / UNICEF Nutrition Assessment, Washington DC and New York: World Bank and UNICEF

Sabir, Muhammad (2011) 'Financial Implications of 7th NFG Award and its Impact on Social Services', submitted for 26th Annual General Meeting and Conference of the Pakistan Society of Development Economists, Islamabad, 28-30 December 2010

Walt, G. and Gilson, L. (1994) 'Reforming the Health Sector in Developing Countries: The Central Role of Policy Analysis', Health Policy Plan 9.4: 353-70 